\title{
Neurilemmoma of the ciliary body: report of a case
}

\author{
RENATO ROSSO,${ }^{1}$ ROBERTO COLOMBO,${ }^{2}$ AND GIUSEPPE RICEVUTI ${ }^{1}$ \\ From the ${ }^{1}$ Institute of Pathologic Anatomy, University of Pavia, Pavia, and the \\ ${ }^{2}$ Department of Ophthalmology, University of Pavia, Pavia, Italy
}

SUMMARY A case of ciliary body neurilemmoma is described. This neoplasm is extremely rare in the uveal tract and has been reported only once in the ciliary body. After extensive clinical studies of the rapidly growing tumour enucleation was performed. Subsequent histological examination showed typical features of highly vascular benign neurilemmoma. The main clinical and pathological features are reported and diagnostic problems are discussed.

Neurogenic tumours of the uveal tract are uncommon. Most of the cases described are of neurofibromas arising in course of von Recklinghausen's disease. Among the neoplasms originating in the nerves of the anterior segment of the globe, benign neurilemmomas (schwannomas) are the rarest. We could find only 6 cases reported in the world literature, in one of which the tumour was located in the ciliary body. ${ }^{1-6}$ The sporadic incidence of uveal neurilemmomas and their lack of distinctive features gave no clue to the correct preoperative diagnosis. The clinical findings were indistinguishable from those presented by uveal leiomyomas, plexiform neurofibromas, and amelanotic malignant melanomas.

\section{Case report}

A 40-year-old Caucasian woman presented in May 1982 complaining of one month of increasing blurring of vision on the temporal side of left eye. There was no previous history of systemic or ocular diseases apart from an impairment of vision in the left eye due to uncorrected astigmatism.

On examination the vision in the right eye was 20/20 and in the left 20/200; after correction of the astigmatism the left eye vision was 20/50. The right fundus, anterior segments, and intraocular pressure were normal. In the nasal part of left conjunctiva and sclera some ectatic blood vessels were seen; the patient stated they had been present from childhood. Light anisocoria was noticeable, with a greater diameter of the right pupil. Behind the iris a protruding, brownish mass was seen occupying much of the pupillary field (Fig. 1).

Correspondence to Dr R. Colombo, Clinica Oculistica dell'Università di Pavia, Dipartimento di Oftalmologia, p.le Golgi 2, 27100 Pavia, Italy.

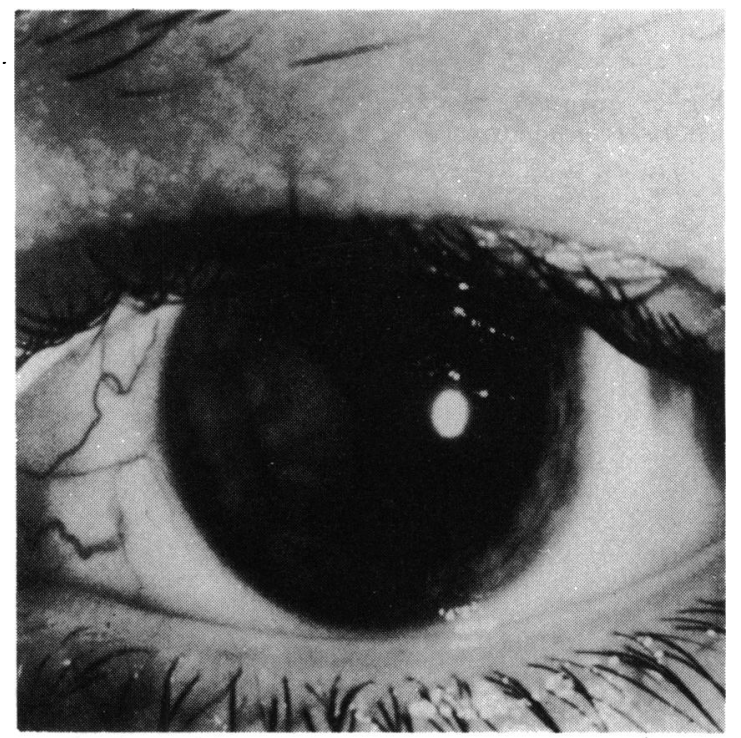

Fig. 1 The brownish highly vascular neoplastic mass protruding behind the iris.

Fluorescein angiography showed abnormal vasculature in the tumour and confirmed the ophthalmoscopic finding of ectatic capillaries on the tumour surface. Echographic examination revealed a rather homogeneous neoplasm of more than $1 \mathrm{~cm}$ in its greatest diameter, with a smooth surface, and apparently arising from the nasal part of the ciliary body, where a secondary retinal detachment was noticeable. On the basis of these findings the differential diagnosis lay between haemangioma, malignant melanoma, and metastatic tumour.

A careful investigation of the patient was performed comprising hepatic scintigraphy and 


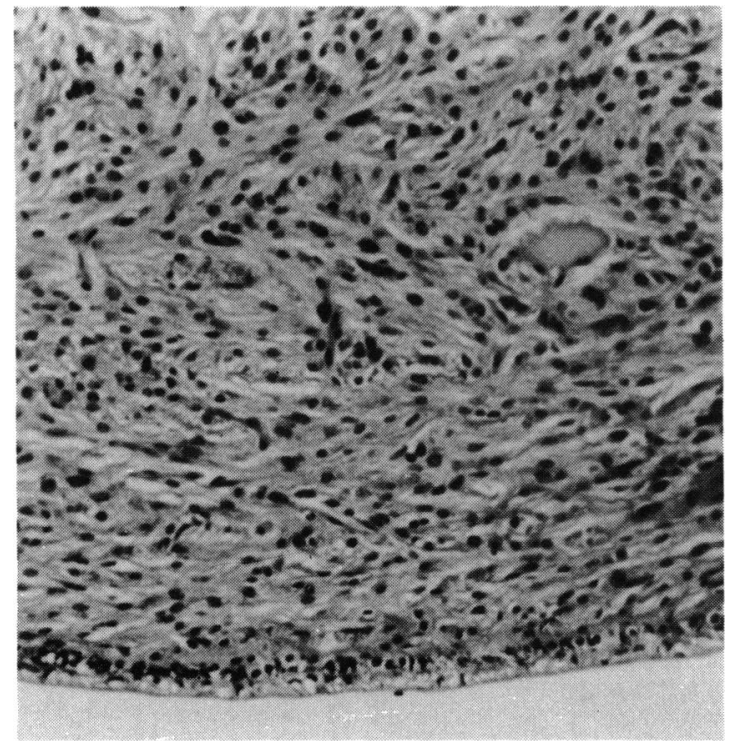

Fig. 2 Schwann tumour cells arranged in waves, drifts, and whorls. (Haematoxylin and eosin, $\times 140$ ).

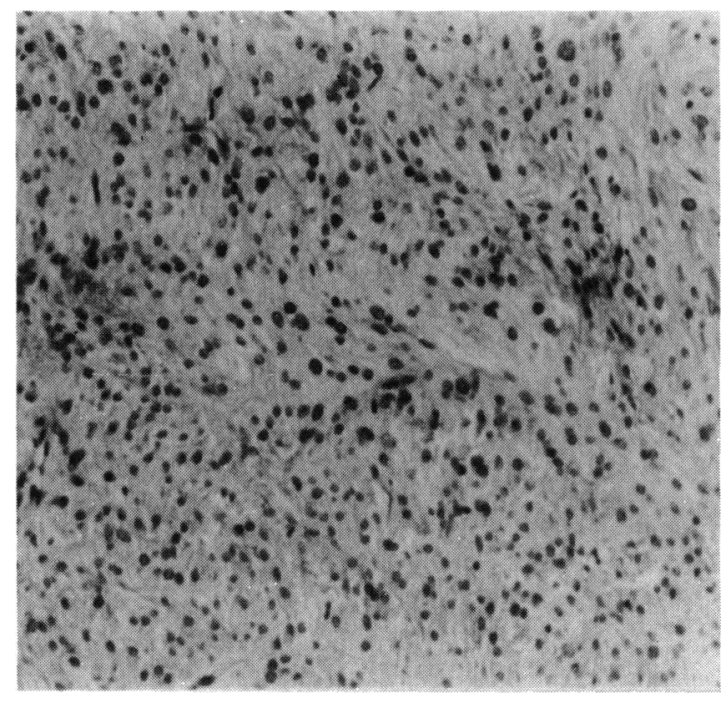

Fig. 3 Palisading of neoplastic cells. (Haematoxylin and eosin, $\times 190$ ).

urinary melanin tests, but nothing of note was found. Owing to a progressive increase in size of the tumour, with continuous impairment of the visual acuity, the lesion was thought to be malignant. It was tentatively interpreted as malignant melanoma, and on this basis an enucleation was decided upon. During operation no extraocular extension was seen. The postoperative course was uneventful.

\section{PATHOLOGICAL FINDINGS}

Macroscopically the tumour was an ovoid mass of about $1.5 \mathrm{~cm}$ in its greatest diameter, growing in the ciliary body with anterior displacement of the iris. The neoplasm was well circumscribed, of firm consistency, and grey-brownish colour. Histologically it was an encapsulated tumour composed of proliferating spindle-shaped cells with enlongated nuclei and indistinct cell membranes. These cells were arranged in waves, drifts, and whorls, assuming the so-called Antoni-A microscopic pattern. In some peripheral areas a tendency to the alignment in palisades of the neoplastic cells was noted (Figs. 2,3). Mitoses were occasional. A very loose, alcian-bluepositive tissue of the so-called Antoni-B type was present centrally. A remarkable finding was hyalinisation and thickening in the walls of most of the tumour vessels. In the peripheral part of the neoplasm the blood capillaries, immersed in an oedematous stroma, appeared markedly ectatic. All these histopathological characteristics led to the diagnosis of uveal neurilemmoma, probably arising from the Schwann cells of a ciliary nerve. Subsequent extensive clinical investigation excluded an undiagnosed von Recklinghausen's disease.

\section{Discussion}

This is the second case of ciliary body neurilemmoma so far reported and the sixth case from the whole uveal tract. In view of its extreme rarity, its clinical behaviour and macroscopic and microscopic aspects deserve particular attention. The tumour grew to a conspicuous size in a short time. A month after the beginning of symptoms it produced severe impairment of vision. The overall appearance of the lesion in the ophthalmoscopic examination was similar to that presented by other choroidal neoplasms, though the presence of ectatic capillaries prominent on the smooth, brownish surface of the tumour seemed unusual, especially in the absence of any haemorrhage. This macroscopic pattern of the tumour had its histological counterpart in high vascularity, so frequently reported in neurilemmomas. Sometimes their blood vessels can be so prominent as to simulate vascular neoplasms.?

Another point of interest is that histology per se does not always allow a clear distinction between benign neurilemmomas and well differentiated malignant schwannomas. In such cases the number of mitoses is of crucial relevance. As a rule the diagnosis of benign neurilemmoma should be doubted if mitoses are present more than occasionally. Thus every effort should be made to ascertain with complete evidence the true nature of the neoplasm. Although extremely rare, neurilemmomas must be 
considered in the differential diagnosis of ciliary body tumours, together with the commoner malignant melanomas, rare haemangiomas, and leiomyomas.

\section{References}

1 Brewitt H, Huerkamp B, Richter K. Ein Neurinom der Aderhaut. Klin Monatsbl Augenheilkd 1976; 169: 750-4.

2 Donovan BF. Neurilemmoma of the ciliary body. Arch Ophthalmol 1956; 55: 672-5.
3 Ferry AP. Lesions mistaken for malignant melanoma of the posterior uvea. Arch Ophthalmol 1964; 72: 463-9.

4 Guillaumat ML, Loisillier MF. Un cas de tumeur choroidienne à structure histologique de neurinome. Bull Soc Ophtalmol Fr 1952; 214-8.

5 Harada M, Tamai M, Takei Y. Neurilemmoma. Folia Ophthalmol Jpn 1977; 28: 773-8.

6 Packard RBS, Harry J. Choroidal neurilemmoma-an unusual clinical misdiagnosis. Br J Ophthalmol 1981; 65: 189-91.

7 Rosai J. Ackerman's surgical pathology. St Louis: Mosby, 1981. 